\section{Successive spatial discrimination reversals in the bat}

\author{
STUART R. ELLINS* and FRED A. MASTERSON \\ University of Delaware, Newark, Del. 19711
}

The performance of five Eptesicus fuscus was studied across a series of nine successive reversals of a spatial discrimination problem. The Ss showed a decrease in mean number of errors across the reversals with an error peak on the third reversal. These results are consistent with the view that improvement across successive reversals (SDRs) is a behavioral indicator of taxonomic differences.

Successive discrimination reversal (SDR) training has been found to be a useful method with which to measure phyletic differences in the learning ability of vertebrates (Bitterman, 1965). This procedure involves the reversal of the reward contingencies in a discrimination learning task each time the discrimination is learned to some criterion. The typical pattern of errors over a series of reversal problems is characterized by an initial increase in errors on early problems, followed by a progressive decrease in errors.

In order to demonstrate that SDR performance is a consistent behavioral indicator of taxonomic differences in learning ability, it is important to study a variety of species. A mammalian species that has not been studied is the bat, of the order Chiroptera, which can be assumed to be representative of the earliest placental mammals (Griffin, 1958).

\section{SUBJECTS}

The Ss were five Eptesicus fuscus which were obtained from caves while in winter hibernation. All Ss were housed in a $.44-\mathrm{m}^{3}$ hardware cloth cage. The Ss were run in two groups. Group I was run approximately 1 year prior to running Group II. Group I consisted of two bats which were maintained on a mixture of ground meal worms blended with dog food, cream cheese, and bananas. Group II consisted of three bats which were maintained on 10 meal worms per day. APPARATUS

The training apparatus for Group I contained a $48 \times 31.7 \times 10 \mathrm{~cm}$ high horizontal crawling alley. At the center of one end of the box was a $10 \times 10 \mathrm{~cm}$ startbox with a wooden door that could be opened by pulling an attached string. At the far end of the box was a $31.7 \times 10 \times 38 \mathrm{~cm}$ vertical section which was divided by a wooden partition forming two vertical climbing alleys. Each climbing alley had sliding doors, one at the top and

* Now at Trenton State College. Trenton. N.J. 08625 . one $15 \mathrm{~cm}$ from the floor. The doors could be closed by pulling attached strings. The sides of the apparatus were made of wood which was painted gray. The floor of the horizontal section and back wall of the vertical section were made of hardware cloth. The top of the horizontal section and front wall of the vertical section were covered with pieces of Plexiglas which were hinged in order to gain entrance into the apparatus. The apparatus was placed inside the home cage with the back wall of the vertical section against the back wall of the home cage. The $76 \times 76 \times 76 \mathrm{~cm}$ home cage was made of hardware cloth. The home cage door remained open during experimental sessions.

The training apparatus for Group II was a $52 \times 39.5 \times 7 \mathrm{~cm}$ high gray wooden box with a hardware cloth floor and rear wall and was covered with hinged Plexiglas sections. At the center of one end of the box was a $10 \times 10 \mathrm{~cm}$ startbox with a door made of hardware cloth with a wooden frame. The door could be opened by pulling a string. The rear of the box was divided into two sections by a plywood partition which protruded

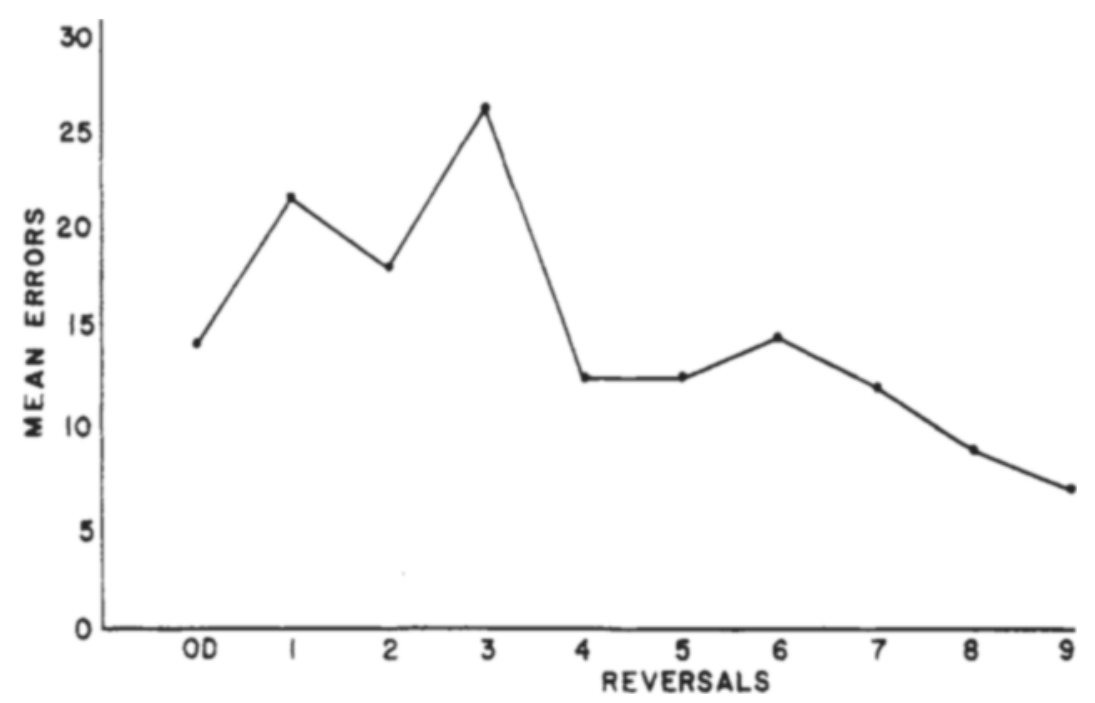

Fig. 1. Mean errors during the original discrimination (OD) and during each of the nine reversal problems. The data for Groups I and II have been combined.
$6 \mathrm{~cm}$ from the center of the rear wall towards the startbox. A $2.5-\mathrm{cm}^{2}$ hole, through which reinforcement could be presented, was cut in the middle of the rear wall of each section. The apparatus was placed on a table and stood on 7-cm-high legs. The $E$ sat behind the far end of the apparatus and was separated from the apparatus by a white sheet.

\section{PROCEDURE}

The Ss in Group I were required to run from the startbox to the rear of the horizontal section and to climb to the top of one of the two vertical alleys. If the $S$ chose to climb the alley designated as positive, it was allowed to leave the apparatus at the top of the alley and remain in the home cage for $3 \mathrm{~min}$, where it hung in a corner in the company of a maintained colony of seven additional bats. This response was employed when preliminary work indicated that social contact with other bats was an effective reward for learning a simple discrimination. If the $S$ chose to climb the alley designated as negative, the alley doors were closed, confining the $S$ to the alley for $3 \mathrm{~min}$. After the $3-\mathrm{min}$ intertrial interval, the $S$ was replaced in the startbox for $10 \mathrm{sec}$ and the next trial commenced.

The Ss in Group II were required to run from the startbox to the rear of the apparatus, a response that required only 10 trials of shaping to learn. If the $S$ ran to the side of the partition designated as positive, it received a half of a mealworm presented with forceps by $E$ through the hole in the rear wall. If the $S$ ran to the side of the partition designated as negative, it was presented with empty forceps at which it snapped. After each trial, the $\mathrm{S}$ was replaced in the startbox, and $10 \mathrm{sec}$ later the next trial was initiated. 


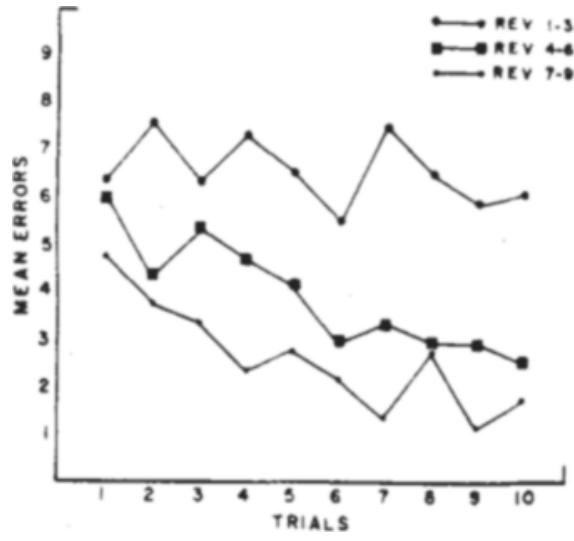

Fig. 2. Mean errors per ordinal trial position within sessions during Reversals 1-3, 4-6, and 7-9.

The Ss in both groups were run for 10 trials per day to a criterion of 9 out of 10 correct responses, at which time the positive and negative response designations were reversed. All Ss were terminated after reaching criterion on nine successive reversal problems.

RESULTS AND DISCUSSION

Figure 1 shows that the mean number of errors for all Ss tended to decrease across the nine reversals with an error peak on the third reversal. The data for Groups I and II were combined because of the similarity of the performances of the groups. An analysis of variance with reversals as repeated measures indicated a significant reversal effect $(F=2.27$, df $=9 / 27, p<.05$ ). The group effect was not significant $(F=0.58, d f=1 / 3$, p $>.05$ ). A Newman-Keuls test with repeated measures (Winer, 1962) indicated that performance on the third reversal $w$ as significantly different from performance on the ninth reversal $(p<.05)$. This result is consistent with previous results which have indicated a decrease in errors across spatial SDR problems.

It has been suggested that the locus of the error peak may be an important measure for ranking species (Gossette \& Gossette, 1967). The present data (Fig. 1) indicate fewer errors on the original discrimination (OD) than on the first reversal. The displacement of the error peak to the third reversal may be indicative of the low taxonomic status of bats relative to that of other mammals, since most commonly studied mammals show error peaks on the first or second reversals. Gossette \& Gossette (1967) found that the error peak produced by "lower order" birds occurred later in a series of reversals than did the peak produced by "higher order" birds. It has also been suggested that the location of the error peak may be related to task difficulty (Gossette \& Brown, 1967). This analysis, however, must await further comparative investigation with bats.

Figure 2 shows the distribution of mean errors across the 10 ordinal trial positions within sessions. The function representing Reversals $1-3$ indicates that in the initial reversals the within-session errors tend to be evenly distributed across trials. This result differs from that of previous studies using birds and monkeys (Gossette \& Cohen, 1966; Gossette, Gossette, \& Inman, 1966; Gossette \& Inman, 1966), which found a roughly linear drop in errors across trials in all reversals. Apparently the rate of learning during the first reversals was considerably slower in the present experiment than in the other experiments. The functions representing Reversals 4-6 and 7-9 are, however, consistent with previous studies, indicating a linear decline in number of errors across trials. Although previous studies have shown that errors tend to occur during the initial trials of the final reversal sessions, this might also have occurred in the present experiment had the experiment been carried out to single-error reversal.

Because bats are taxonomically intermediate to birds and higher mammals, both of which show improvement on spatial SDR tasks, it would be assumed that bats would also show spatial SDR improvement. This assumption is borne out by the present data.

\section{REFERENCES}

BITTERMAN, M. E. The evolution of intelligence. Scientific American, 1965 $212,92-100$.

GOSSETTE, R. L., \& BROWN; H. R. The scaling of relative task difficulty across spatial, brightness, and form successive discrimination reversal (SDR) problems with Capuchin monkeys. Psychonomic Science, 1967, 9, 1-2.

GOSSETTE, R. L., \& COHEN, H. Error reduction by pigeons on a spatial successive reversal task under conditions of noncorrection. Pstchological Reports, $1966,18,367-370$.

GOSSETTE, R. L., \& GOSSETTE, M. F Examination of the reversal index (RI) across fifteen different mammalian and avian species. Pexceptual \& Motor Skills, $1967,24,987-990$

GOSSETTE, R. L.. GOSSETTE, M. F., \& INMAN. N. Successive discrimination reversal performance by the Greater Hill Myna. Animal Behaviour, 1966, 14. $50-53$.

GOSSETTE, R. L., \& INMAN, N Comparison of spatial successive discrimination reversal performances of two groups of New World monkeys. Perceptual \& Motor Skills, 1966, 23, 169-170.

GRIFFIN, $D$, Listening in the dark. New Haven: Yale University Press, 1958.

WINER, B. J. Statistical principles in experimental design. New York McGraw-Hill, 1962. 